http://jmscr.igmpublication.org/home/ ISSN (e)-2347-176x ISSN (p) 2455-0450 crossref DOI: https://dx.doi.org/10.18535/jmscr/v10i2.14

\title{
Prevalance of H. Pylori Infection in Patients of Cirrhosis of Liver with Its Etiological Correlation
}

\author{
Authors \\ Dr Mahendra Pratap Singh ${ }^{1}$, Dr A K Yadav ${ }^{2 *}$, Dr Balvir Singh ${ }^{3}$, Dr A Gautam ${ }^{4}$ \\ ${ }^{1}$ Assistant professor Peoples medical college Bhopal Madhya Pradesh \\ ${ }^{2}$ Consultant general medicine district hospital Orai Jalaun Uttar Pradesh \\ ${ }^{3}$ Professor, P.G. Department of Medicine, S.N. Medical College, Agra \\ ${ }^{4}$ Associate professor Department of medicine SNMC Agra \\ *Corresponding Author \\ Dr Amit Kumar Yadav \\ Consultant General Medicine, District Hospital Orai Jalaun Uttar Pradesh, Uttar Pradesh, INDIA
}

Abstract
Objective: Prevalance of h. pylori infection in patients of cirrhosis of liver with its etiological correlation
Method: 100 diagnosed cases (newly and previously diagnosed cases) of chronic liver disease admitted in
Medicine Department at S.N. Medical College, Agra were included in the study. The duration of study was 18
months (during the period from June 2015 to January 2017).A thorough history, physical examination and
Investigations were done, patients were categorized in different CHILD PUGH Grades and also categorized
according to the different grades of esophageal varices and hepatic encephalopathy.
Result: In our study, 100 patients of chronic liver disease were enrolled, out of which 65 patients were male and
35 were female. Most of the patients were in the $41-50$ years age group. The most common presenting complains of
the patients in our study was ascites (62\%) followed by hepatic encepahalopathy (46\%) and malena (43\%). Among
the 100 patients, the most common cause of cirrhosis in our study was alcohol abuse (42\%), followed by Hepatitis
$B(32 \%)$ and Hepatitis $C$ (22\%). In 4 patients, no obvious cause of cirrhosis could be identified and they were
labelled as idiopathic.
Conclusion: All the patients of liver cirrhosis should be evaluated at the earliest for the presence of H pylori
infection. The early detection and consequent eradication of H pylori infection may reduce the severity of
complications like bleeding esophageal varices, portal gastropathy and hepatic encephalopathy.
Keywords: liver cirrhosis, H pylori, Child Pugh grade, Esophageal varices, Hepatic encephalopathy.

\section{Introduction}

Cirrhosis a condition that is defined histopathologically and has a variety of clinical manifestations and complications, some of which can be life threatening. Regardless of the cause of cirrhosis, the pathologic features consist of the development of fibrosis to the point that there is architectural distortion with the formation of regenerative nodules. This results in a decrease in hepatocellular mass, and thus function, and an alteration of blood flow.
Clinical features of cirrhosis are the result of pathologic changes and mirror the severity of the liver disease. Most hepatic pathologists provide an assessment of grading and staging when evaluating liver biopsy samples ${ }^{1}$. A reliable staging system to stage cirrhosis clinically is the modified Child-Pugh classification with a scoring system of 5-15: scores of 5 and 6 being ChildPugh class A (consistent with "compensated cirrhosis"), scores of 7-9 indicating class B, and 10-15 indicating class $C^{1}$. The Child-Pugh score is 
a reasonably reliable predictor of survival in many liver diseases and predicts the likelihood of major complications of cirrhosis such as bleeding from varices and spontaneous bacterial peritonitis.

Cirrhosis is a major health problem with high incidence and prevalence worldwide. It is associated with alteration in the gastrointestinal mucosa, with increased risk for peptic ulcer disease $^{2}$. Port hypertensive gastropathy (PHG) is one of the clinically important gastric mucosal lesions because it may cause acute or chronic gastro intestinal blood loss leading to anaemia. The prevalence of PHG is shown to be closely associated with the severity of cirrhosis assessed by Child-Pugh classification, being more common in Child-Pugh C than in Child Pugh A patients ${ }^{3}$.

Several pathophysiological mechanisms have been postulated for PHG. They include increased serum gastrin $^{4}$ leading to increased acid secretion, alteration in blood flow ${ }^{5-6}$, decreased secretion of postglandin in the gastric mucosa ${ }^{7}$ and the presence of Helicobacter pylori (H. Pylori) infection $^{8}$.

Infection by $H$. pylori is highly prevalent, especially in low socio-economic strata of developing countries, being responsible for lesions like gastroduodenal erosions and ulcers. In patients with liver cirrhosis, their prevalence is controversial $^{9}$, as well as the existence of associations with PHG. Knowledge of the prevalence of infection by $\mathrm{H}$. pylori in patients with liver cirrhosis and the study of the association with PHG, could be useful to better understand the pathogenesis of PHG and the evaluation of possible additive effect on production of PHG, when the two conditions are present. If $\mathrm{H}$. pylori infection is found to contribute to the pathogenesis of PHG, then eradication of $\mathrm{H}$. pylori should be beneficial in the management of PHG bleeding which usually results in anemia.

\section{Materials and Methods}

This was a hospital based cross sectional observational study and was carried out in Post Graduate Department of Medicine, S.N. Medical College and Hospital, Agra. 100 diagnosed cases (newly and previously diagnosed cases) of chronic liver disease admitted in wards of Medicine Department at S.N. Medical College, Agra were included in the study. The duration of study was 18 months (during the period from June 2015 to January 2017).

Inclusion Criteria: 1. Age > 14 years, 2. Patients of cirrhosis of liver with $\mathrm{H}$. pylori infection who have gastric erosions diagnosed by UGIE

Exclusion Criteria: 1. Age < 14 years 2. Patients on treated with antibiotics and PPI prior to inclusion within 4 weeks of duration.

Chronic liver disease patients who were previously diagnosed or diagnosed in wards were carefully selected using criteria laid down. Written informed consent was taken from all the patients. A thorough history was taken and physical examination was done, patients were subjected to following investigations: Liver function tests, S. Uric Acid, Prothombin time, Investigations on basis of Etiology, HIV, Viral Markers HbsAg, Anti HCV, USG ABDOMEN, UGIE, H. Pylori (detected by taking tissue on UGIE diagnosed by rapid urease test)

From the above patients were categorized in different CHILD PUGH Grades. Patients were also categorized according to the different grades of esophageal varices and hepatic encephalopathy. The prevalence of $\mathrm{H}$ pylori infection was calculated in these sub groups of patients and the severity of these complications was correlated with the presence of $\mathrm{H}$ pylori infection

\section{Results and Observations}

This study was carried out at P.G. Department of Medicine, S.N. Medical College, Agra. Total 100 patients of chronic liver disease were included in the study.

Out of the 100 patients 35 were female and 65 were male. 
Table No. 1: Distribution of Patients according to Etiology of Cirrhosis along with Child Pugh Scoring Grading

\begin{tabular}{|l|c|c|c|c|}
\hline & Grade A & Grade B & Grade C & Total \\
\hline Alcoholic & 8 & 18 & 16 & $\mathbf{4 2}$ \\
\hline Hepatitis B & 14 & 13 & 5 & $\mathbf{3 2}$ \\
\hline Hepatitis C & 8 & 12 & 2 & $\mathbf{2 2}$ \\
\hline Idiopathic & 2 & 1 & 1 & $\mathbf{4}$ \\
\hline Total & $\mathbf{3 2}$ & $\mathbf{4 4}$ & $\mathbf{2 4}$ & $\mathbf{1 0 0}$ \\
\hline
\end{tabular}

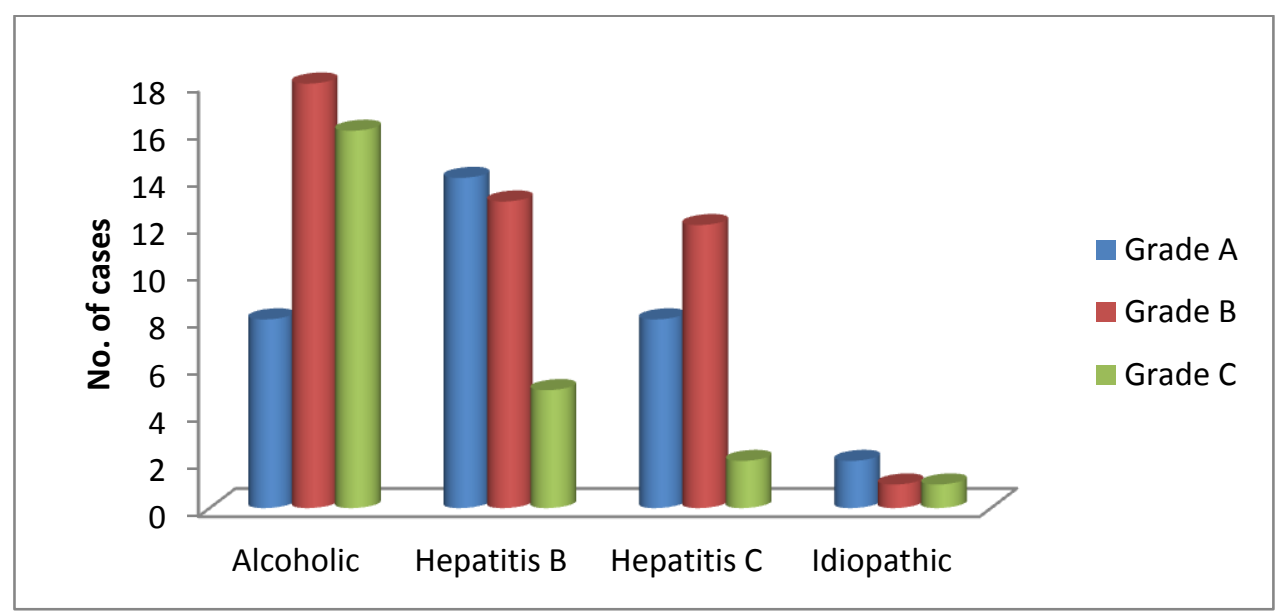

Out of 100 patients, the cause of chronic liver disease was alcohol in $42 \%$ patients, hepatitis B in $32 \%$ patients, hepatitis $\mathrm{C}$ in $22 \%$ patients, and idiopathic in $4 \%$ patients. Among the 100 patients in our study, 32 patients were in Child Pugh Grade A, 44 patients belonged to Child Pugh Grade B and 24 patients belonged to Child Pugh Grade C.

Table 2: Showing Distribution of H. pylori infection in cirrhotic patient along with their etiology

\begin{tabular}{|l|c|c|c|c|c|}
\hline \multirow{2}{*}{ Etiology } & \multicolumn{2}{|c|}{ H Pylori Present } & \multicolumn{2}{c|}{ H Pylori Absent } & $\begin{array}{c}\text { Total Patients } \\
(\mathrm{N}=100)\end{array}$ \\
\cline { 2 - 5 } & Number & Percentage & Number & Percentage & 42 \\
\hline Alcohol & 14 & $33.33 \%$ & 28 & $66.67 \%$ & 32 \\
\hline Hepatitis B & 18 & $56.25 \%$ & 14 & $43.75 \%$ & 22 \\
\hline Hepatitis C & 13 & $59.09 \%$ & 9 & $40.91 \%$ & 4 \\
\hline Idiopathic & 1 & $25 \%$ & 3 & $75 \%$ & 4 \\
\hline
\end{tabular}

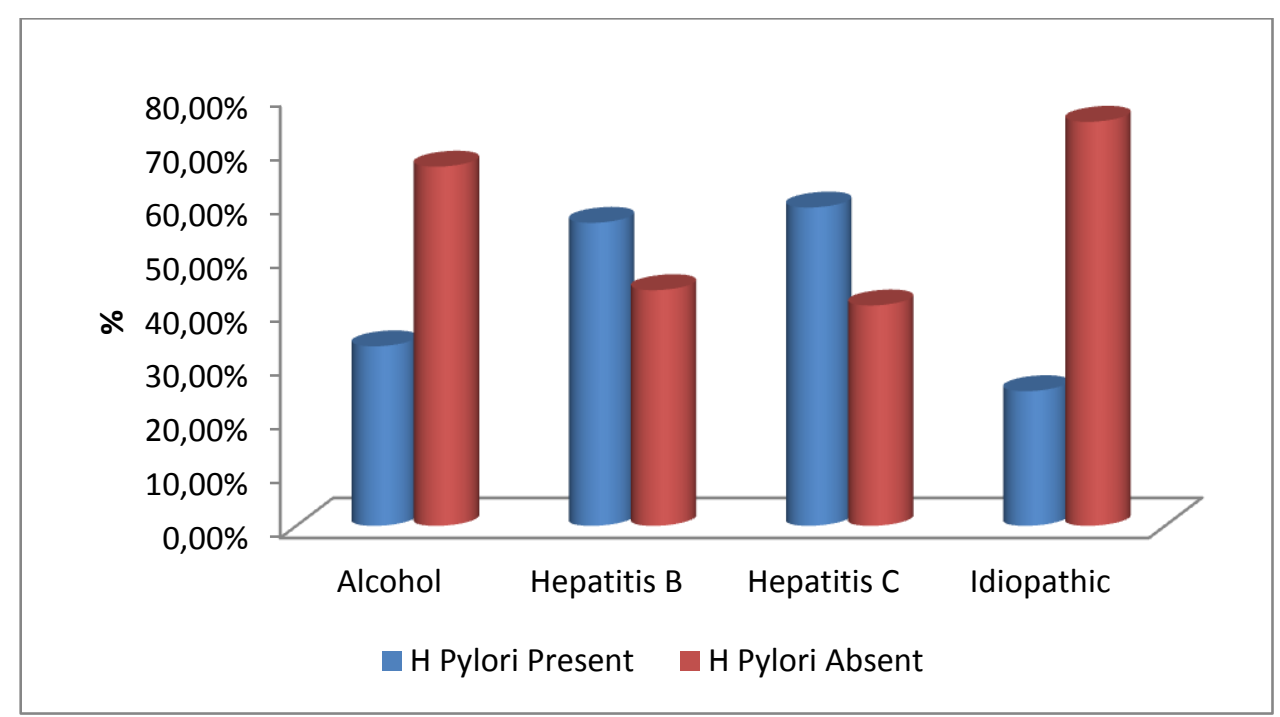

Among the 42 patients with alcoholic cirrhosis, $\mathrm{H}$ pylori infection was seen in 14 patients $(33.33 \%)$ while it was absent in 28 patients $(66.67 \%)$.
In patients with cirrhosis due to Hepatitis $\mathrm{B}, \mathrm{H}$ pylori infection was present in 18 patients $(56.25 \%)$ and absent in 14 patients $(43.75 \%)$. In 
patients with cirrhosis due to Hepatitis $\mathrm{C}, \mathrm{H}$ pylori infection was present in 13 patients (59.09\%) and absent in 9 patients $(40.91 \%)$. Among the patients with idiopathic cirrhosis, $\mathrm{H}$ pylori infection was present in 1 patient $(25 \%)$ and absent in 3 patients $(75 \%)$.

Table 6: Distribution of H. Pylori infection in various grades of esophageal varices in the cirrhotic patients

\begin{tabular}{|c|c|c|c|c|c|c|c|c|c|c|c|c|}
\hline \multirow{2}{*}{$\begin{array}{l}\text { Grade of } \\
\text { Esophageal } \\
\text { varices }\end{array}$} & \multicolumn{3}{|c|}{ Alcoholic } & \multicolumn{3}{|c|}{ Hepatitis B } & \multicolumn{3}{|c|}{ Hepatitis C } & \multicolumn{3}{|c|}{ Idiopathic } \\
\hline & $\begin{array}{c}\text { Total } \\
\text { Patients }\end{array}$ & $\begin{array}{c}\text { H. } \\
\text { Pylori } \\
\text { Present }\end{array}$ & $\begin{array}{c}\text { H. } \\
\text { Pylori } \\
\text { Absent }\end{array}$ & $\begin{array}{c}\text { Total } \\
\text { Patients }\end{array}$ & $\begin{array}{c}\text { H. } \\
\text { Pylori } \\
\text { Present }\end{array}$ & $\begin{array}{c}\text { H. } \\
\text { Pylori } \\
\text { Absent }\end{array}$ & $\begin{array}{c}\text { Total } \\
\text { Patients }\end{array}$ & $\begin{array}{c}\text { H. } \\
\text { Pylori } \\
\text { Present }\end{array}$ & $\begin{array}{c}\text { H. } \\
\text { Pylori } \\
\text { Absent }\end{array}$ & $\begin{array}{c}\text { Total } \\
\text { Patients }\end{array}$ & $\begin{array}{c}\text { H. } \\
\text { Pylori } \\
\text { Present }\end{array}$ & $\begin{array}{c}\text { H. } \\
\text { Pylori } \\
\text { Absent }\end{array}$ \\
\hline Grade 0 & 18 & 3 & 14 & 13 & 5 & 8 & 7 & 3 & 4 & 2 & 0 & 2 \\
\hline Grade 1 & 9 & 3 & 6 & 9 & 6 & 3 & 6 & 4 & 2 & 1 & 0 & 1 \\
\hline Grade 2 & 11 & 6 & 5 & 6 & 4 & 2 & 7 & 4 & 3 & 1 & 1 & 0 \\
\hline Grade 3 & 4 & 2 & 2 & 4 & 3 & 1 & 2 & 2 & 0 & $\mathbf{0}$ & 0 & 0 \\
\hline Total & 42 & 14 & 28 & 32 & 18 & 14 & 22 & 13 & 9 & 4 & 1 & 3 \\
\hline
\end{tabular}

The above table shows the distribution of $\mathrm{H}$. Pylori infection in various grades of esophageal varices in the cirrhotic patients. $\mathrm{H}$ pylori infection was seen in 12 out of 40 patients in Grade $0 \mathrm{EV}$,
13 out of 25 patients in Grade $1 \mathrm{EV}, 15$ out of 25 patients in Grade $2 \mathrm{EV}$ and 7 out of 10 patients in Grade 3 EV.

Table 7: Showing distribution of H. Pylori infection in various grades of hepatic encephalopathy among chronic liver disease patients

\begin{tabular}{|c|c|c|c|c|c|c|c|c|c|c|c|c|}
\hline \multirow{2}{*}{$\begin{array}{l}\text { Grade of } \\
\text { Hepatic } \\
\text { Encephelopathy }\end{array}$} & \multicolumn{3}{|c|}{ Alcoholic } & \multicolumn{3}{|c|}{ Hepatits B } & \multicolumn{3}{|c|}{ Hepatis C } & \multicolumn{3}{|c|}{ Idiopathic } \\
\hline & & 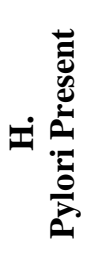 & 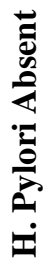 & 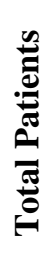 & 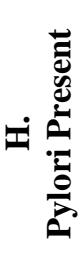 & 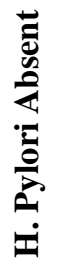 & 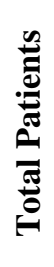 & 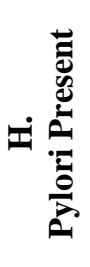 & 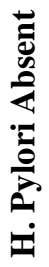 & 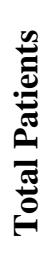 & 可 & 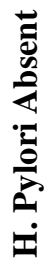 \\
\hline Grade 0 & 18 & 3 & 15 & 10 & 4 & 6 & 6 & 3 & 3 & 2 & $\mathbf{0}$ & 2 \\
\hline Grade 1 & 10 & 3 & 7 & 9 & 5 & 4 & 8 & 5 & 3 & 1 & $\mathbf{0}$ & 1 \\
\hline Grade 2 & 8 & 4 & 4 & 8 & 5 & 3 & 5 & 3 & 2 & 1 & 1 & $\mathbf{0}$ \\
\hline Grade 3 & 6 & 4 & 2 & 5 & 4 & 1 & 3 & 2 & 1 & $\mathbf{0}$ & $\mathbf{0}$ & $\mathbf{0}$ \\
\hline Total & 42 & 14 & 28 & 32 & 18 & 14 & 22 & 13 & 9 & 4 & 1 & 3 \\
\hline
\end{tabular}

$\mathrm{H}$ pylori infection was seen in 10 out of 36 patients with grade $0 \mathrm{HE}, 13$ out of 28 patients of
Grade $1 \mathrm{HE}, 13$ out of 22 patients with Grade 2 $\mathrm{HE}$, and 10 out of 14 patients with Grade $3 \mathrm{HE}$.

Table 8: Showing distribution of H. Pylori infection in various Child Pugh Grade among chronic liver disease patients

\begin{tabular}{|c|c|c|c|c|c|c|c|c|c|c|c|c|}
\hline \multirow{2}{*}{$\begin{array}{l}\text { Child } \\
\text { Pugh } \\
\text { Stage }\end{array}$} & \multicolumn{3}{|c|}{ Alcoholic } & \multicolumn{3}{|c|}{ Hepatitis B } & \multicolumn{3}{|c|}{ Hepatitis C } & \multicolumn{3}{|c|}{ Idiopathic } \\
\hline & 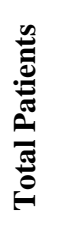 & 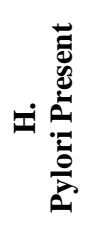 & 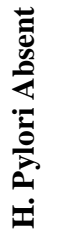 & 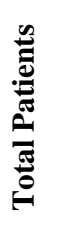 & 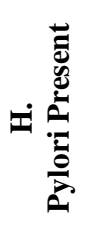 & 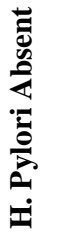 & 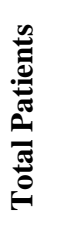 & 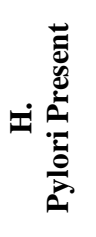 & 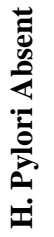 & 苛 & 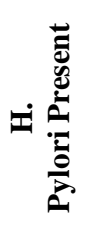 & 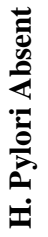 \\
\hline Grade A & 8 & 2 & 6 & 14 & 7 & 7 & 8 & 4 & 4 & 2 & 0 & 2 \\
\hline Grade B & 18 & 5 & 13 & 13 & 8 & 5 & 12 & 8 & 4 & 1 & 0 & 1 \\
\hline Grade C & 16 & 7 & 9 & 5 & 3 & 2 & 2 & 1 & 1 & 1 & 1 & 0 \\
\hline Total & 42 & 14 & 28 & 32 & 18 & 14 & 22 & 13 & 9 & 4 & 1 & 3 \\
\hline
\end{tabular}




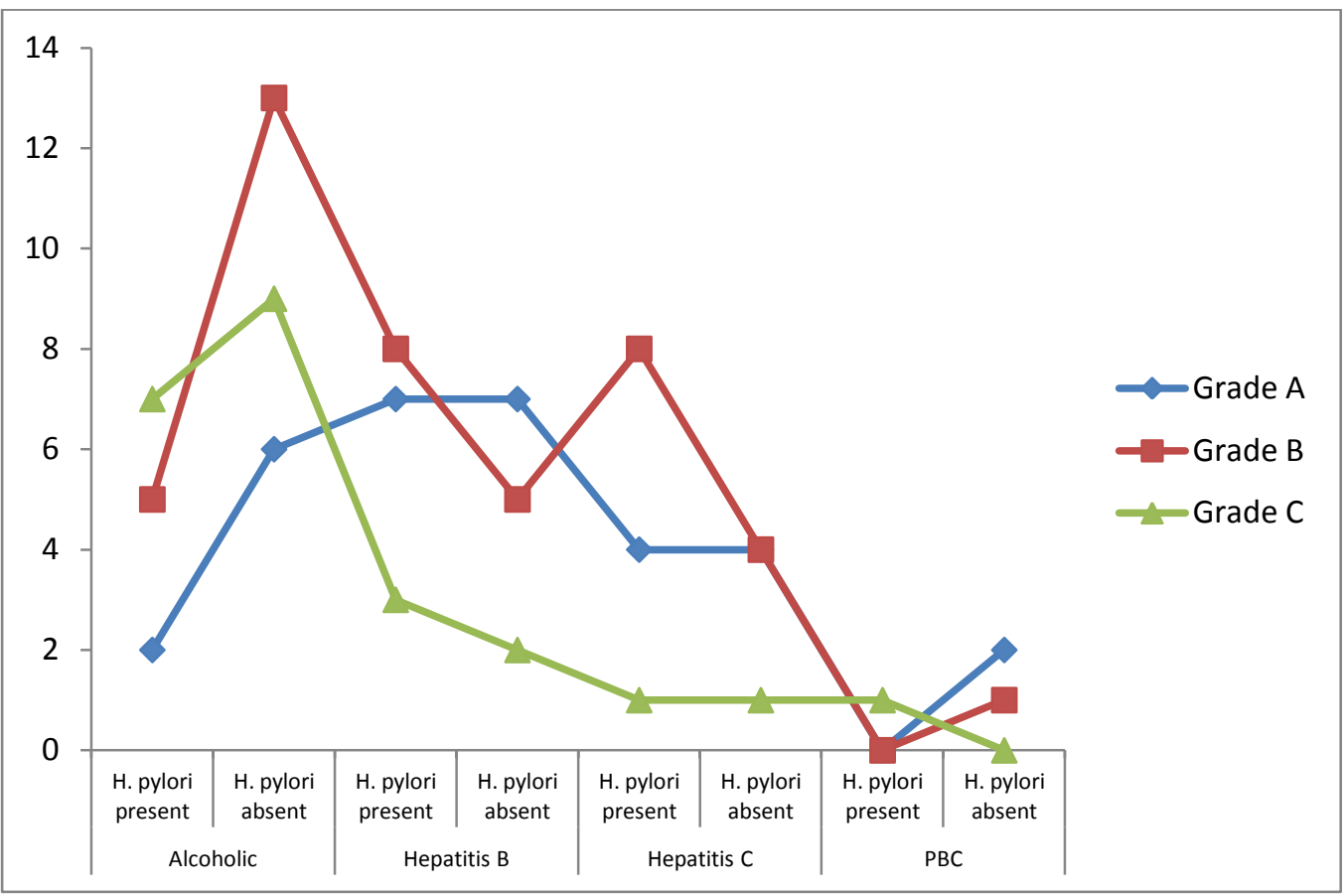

In the patients of alcoholic cirrhosis, $\mathrm{H}$. pylori infection was seen in 2 patients of CP Grade A, 5 patients of CP Grade B and 7 patients of $\mathrm{CP}$ Grade C.Among Hepatitis B cirrhotic patients, H. pylori infection was present in 7 patients of $\mathrm{CP}$ Grade A, 8 patients of CP Grade B and 3 patients of CP Grade C.Out of 22 patients of Hepatitis C cirrhosis, H. pylori infection was present in 4 patients of CP Grade A, 8 patients of CP Grade B and 1 patients of CP Grade C. In the patients of idiopathic Cirrhosis, H. pylori infection was seen in1 patient of CP Grade C.

Table 9: Showing prevalence of $\mathrm{H}$ pylori infection among patients with and without Portal Hypertensive Gastropathy.

\begin{tabular}{|l|c|c|c|c|c|}
\hline & H pylori Present & Percentage & H pylori Absent & Percentage & P value \\
\hline $\begin{array}{l}\text { PHG Present } \\
\text { (N=54) }\end{array}$ & 32 & $59.25 \%$ & 22 & $41.75 \%$ & \multirow{2}{*}{$\mathrm{P}<0.014$} \\
\cline { 1 - 5 } $\begin{array}{l}\text { PHG Absent } \\
\text { (N=46) }\end{array}$ & 14 & $30.43 \%$ & 32 & $69.57 \%$ & \\
\hline
\end{tabular}

On endoscopy (UGIE), PHG was present in 54 patients out of which $\mathrm{H}$ pylori infection was seen in 32 patients $(59.25 \%)$ and absent in 22 patients (41.75\%). PHG was absent in 46 patients, out of whom $\mathrm{H}$ pylori infection was seen in 14 patients (30.43\%) and absent in 32 patients $(69.57 \%)$.

\section{Discussion}

In our study, 100 patients of chronic liver disease were enrolled, out of which 65 patients were male and 35 were female. Most of the patients were in the 41-50 years age group.

The most common presenting complains of the patients in our study was ascites $(62 \%)$ followed by hepatic encepahalopathy $(46 \%)$ and malena (43\%).

Among the 100 patients, the most common cause of cirrhosis in our study was alcohol abuse (42\%), followed by Hepatitis B (32\%) and Hepatitis C (22\%). In 4 patients, no obvious cause of cirrhosis could be identified and they were labelled as idiopathic. Joanna Pogorzelska et $\mathbf{a l}^{\mathbf{1 0}}$ and Dr Shanid Abdul Sathar et al $^{11}$ in their study has found alcohol abuse as most common cause of cirrhosis (38\%) followed by Hepatitis C (28.57\%) and Hepatitis B $(21 \%)$.

The patients were evaluated in different groups as per the Child Pugh Grading. Most of the patients in our study belonged to Child Pugh Grade B 
(44\%) followed by Child Pugh Grade A (32\%) and Child Pugh Grade C (24\%). In their study, Joanna Pogorzelska et $\mathbf{a l}^{10}$ found that among total 147 patients, 33\% were in Child Pugh Grade A, $43 \%$ in Child Pugh Grade B and 24\% in Child Pugh Grade C.

Among the 100 patients $\mathrm{H}$ pylori infection was seen in $46 \%$ patients while it was absent in rest $54 \%$ patients. Similarly, the prevalence of $\mathrm{H}$ pylori infection was seen $46.9 \%$ by Joanna Pogorzelska et al $^{\mathbf{1 0}}, 44.3 \%$ by Dr Shanid Abdul Sathar et al $^{\mathbf{1 1}}$, and $50.20 \%$ by Calvet X. Sanfeliu I, Musulen E et al $^{\mathbf{1 2}}$ respectively.

Among the different causes of cirrhosis, $\mathrm{H}$ pylori infection was most prevalent in patients of Hepatitis C (59.09\%), followed by Hepatits B $(56.25 \%)$ and alcohol abuse $(33.33 \%)$. Thus, the infectious causes of cirrhosis tend to have a higher prevalence of $\mathrm{H}$ pylori infection as compared to others.

$\mathrm{H}$ pylori infection was seen in 12 out of 40 patients in Grade $0 \mathrm{EV}, 13$ out of 25 patients in Grade 1 EV, 15 out of 25 patients in Grade 2 EV and 7 out of 10 patients in Grade 3 EV. Thus, it is clear that with the advance in Grade of esophageal varices, the prevalence of $\mathrm{H}$ pylori infection increases. Among all the patients of esophageal varices, $\mathrm{H}$ pylori infection was seen in $58.33 \%$ ( $\mathrm{p}<0.05$ ). This result was consistent with that has been seen in various other studies eg. Shekhar Puri et $\mathbf{a l}^{\mathbf{1 3}}$ found $\mathrm{H}$ pylori infection in 55\% patients with portal hypertensive gastropathy and similarly Shanid Abdul Sathar et $\mathbf{~ a l}^{\mathbf{1 4}}$ found $\mathrm{H}$ pylori infection in $44.3 \%$ patients with $\mathrm{PHG}$.

$\mathrm{H}$ pylori infection was seen in 10 out of 36 patients with grade $0 \mathrm{HE}, 13$ out of 28 patients of Grade $1 \mathrm{HE}, 13$ out of 22 patients with Grade 2 $\mathrm{HE}$, and 10 out of 14 patients with Grade $3 \mathrm{HE}$. Thus, the prevalence of $\mathrm{H}$ pylori infection increased among the patients with higher grades of hepatic encephalopathy. Among these patients of $\mathrm{HE}, 56.25 \%$ patients had $\mathrm{H}$ pylori infection ( $\mathrm{p}$ $<0.05)$. Kini $\mathbf{D}$ et $\mathbf{a l}^{\mathbf{1 5}}$ found $\mathrm{H}$ pylori infection in $53.44 \%$ patients having hepatic encephalopathy. Chritian Schulz et $\mathbf{a l}^{\mathbf{1 6}}$ found the prevalence of $\mathrm{H}$ pylori infection in $29.24 \%$ patients. Similarily, Săndulache $\mathbf{L}$ et $\mathbf{a l}^{\mathbf{1 7}}$ found $\mathrm{H}$ pylori infection to be $55.61 \%$ patients.

The prevalence of $\mathrm{H}$ pylori infection among the different grades of Child Pugh Score has also been observed. In Child Pugh Grade A, 13 out of 32 patients had $\mathrm{H}$ pylori infection. And, 21 out of 44 patients in Child Pugh Grade B and 12 out of 24 patients in Child Pugh Grade $\mathrm{C}$ had $\mathrm{H}$ pylori infection ( $\mathrm{p}<0.05$ ). Thus, this again shows that $\mathrm{H}$ pylori infection was more prevalent in patients among the higher Child Pugh Grades which are having more advance diseases as well as grades of Hepatic encepahlopathy.

PHG was present in 54 patients out of which $\mathrm{H}$ pylori infection was seen in 32 patients $(59.25 \%)$ and absent in 22 patients $(41.75 \%)$. PHG was absent in 46 patients, out of whom $\mathrm{H}$ pylori infection was seen in 14 patients (30.43\%) and absent in 32 patients $(69.57 \%)$. Thus, $\mathrm{H}$ pylori infection was significantly more among the patients with PHG as compared to patients without PHG $(\mathrm{p}<0.05)$.

\section{Summary and Conclusion}

Hence this study concludes:

1. Prevalence of $\mathrm{H}$ pylori infection is fairly common among the patients of chronic liver disease.

2. Prevalence of $\mathrm{H}$ pylori infection is more common in post infectious (Hepatitis B and Hepatitis C) causes of cirrhosis as compared to other etiologies.

3. Prevalence of $\mathrm{H}$ pylori infection was more common among the patients having hepatic encephalopathy and higher prevalence was seen as the grade of HE increased. This may be due to increased blood ammonia levels.

4. On Endoscopy (UGIE) as the grades the esophageal varices and portal gastropathy increased among the patients, the $\mathrm{H}$ pylori infection was seen more frequently. Hence it is clear that chances of bleeding is more in these patients who are $\mathrm{H}$. pylori positive. 
Hence from above observation we emphasize that all the patients of liver cirrhosis should be evaluated at the earliest for the presence of $\mathrm{H}$ pylori infection. $\mathrm{H}$ pylori infection further increased the ammonia level and hence hepatic encephalopathy and bleeding chances in these patients. The early detection and consequent eradication of $\mathrm{H}$ pylori infection may be helpful in reducing the severity of complications like bleeding from esophageal varices, portal hypertensive gastropathy and hepatic encephalopathy.

\section{Bibliography}

1. Longo, Fauci, Kasper, hauser, Jameson, Loscalzo. Harrison principles of Internal Medicine 18th edition. Chapter 308 Page 2592.

2. Rabinovitz M, Yoo YK, Schade RR, Dindzans VJ, Van Thiel DH, Gavilia JS. Prevalence of endoscopic findings in 510 consecutive individuals with cirrhosis evaluated prospectively. Dig. Dis Sc. 1990 ; 35 : 705-710.

3. Sarin SK, Sreenivas DV, Lahoti D, Saraya A. Factors influencing development of portal hypertensive gastropathy in patients with portal hypertension. Gastroenterology $1992 ; 102$ : 994 - 999.

4. Lenz HJ, Hogan DL, Isenberg J1, Intestinal phase of gastric acid secretion in humans with and without portocaval shunt. Gastroenterology. 1985; 89 : 791-796.

5. Sarfeth IJ, Tarnawski A, Mason GR, Mach T, Ivey RJ. Portal hypertension and gastric mucosal injury in rats. Gastroenterology 1983; 84:987-993.

6. Sarfeh IJ, Tarnawski A, Maeda R, Raymont K, Mason GR, Ivey KJ. The gastric mucosa in portal hypertension: effects of topical bile acid. Scand J Gastroentero M 984 ; 9(92): 189 - 194.

7. Arakawa T, Satoh H, Fukuda T, Nakamura $\mathrm{H}, \quad$ Kobayashi K.Endogenous prostaglandin E2 in gastric mucosa of patients with alcoholic cirrhosis and portal hypertension. Gastroenterology 1987 ; 93 :135 - 140.

8. Hopkins RJ, Girardi LS, Turney EA. Relationship between Helicobacter pylori eradication and gastric ulcer and duodenal ulcer reduced recurrence: a review. Gastroenterology, 1996; 110: 1244 - 1252.

9. Malatya HM. Epidemiology of Helicobacter pylori infection Best Pract Res Clin Gastroenterol 2007; 21 : 205 214.

10. Pogorzelska J, Łapińska M, Kalinowska A, Łapiński TW, Flisiak R. Helicobacter pylori infection among patients with liver cirrhosis. European Journal of Gastroenterology \& Hepatology. 2017;29 (10):1161-1165.

11. Dr. Shanid Abdul Sathar, To determine the prevalence of $\mathrm{H}$. pylori infection in cirrhosis patients with $\mathrm{PHG}$, to find out any association of $\mathrm{H}$. pylori infection with PHG and to correlate the severity of PHG with the colonization of $\mathrm{H}$. pylori. Received 6 May 2013; accepted 25 June 2013

12. Calvet X. Sanfeliu I, Musulen E et al. Evaluation of Helicobacter pylori diagnostic methods in patients with liver cirrhosis. Aliment Pharmacol. Ther. 2002; 16: 1283-1289.

13. Puri S, Jain M, Narayan KS, Pandey S, Nijhawan S. Helicobacter pylori infection in patients with portal hypertensive gastropathy owing to liver cirrhosis: Prevalence and relation with severity of gastropathy. J Dig Endosc 2017;8:123-8

14. Shanid Abdul Sathar, Sojan George Kunnathuparambil, SrijayaSreesh et al. Helicobacter pylori infection in patients with liver cirrhosis: prevalence and association with portal hypertensive gastropathy. Ann Gastroenterol 2014; 27 (1): $48-52$ 
15. Kini D, Aggarwal R, Saraswat VA, Naik SR et al "Role of Helicobacter pylori infection in hyperammonemia and subclinical hepatic encephalopathy in cirrhosis of liver"; Indian J Gastroenterol. 2001 Nov-Dec;20(6):237-40

16. Calvet $X$, Navarro $M$, Gil $M$ et al. Epidemiology of peptic ulcer disease in cirrhotic patients: Role of Helicobacter pylori infection. American Journal of Gastroenterology 1998 ; 93 : 2501 - 2507.

17. Săndulache L, Stanciu C et al. "Prevalence of Helicobacter pylori in liver cirrhosis complicated with hepatic encephalopathy"; Rev Med Chir Soc Med Nat Iasi. 2009 Oct-Dec;113(4):1056-60. 